\title{
Directorio básico de fuentes de información especializadas en Patrimonio Arquitectónico existentes en Internet
}

Lo que a continuación se presenta es una guía de recursos de información sobre patrimonio arquitectónico existentes en Internet. La guía ha sido elaborada siguiendo los siguientes pasos:

- Detección y selección de los recursos de información utilizando los índices temáticos y motores de búsqueda generales y especializados más importantes existentes en Internet.

- Clasificación de los recursos seleccionados según la tabla que se presenta a continuación. Cada apartado se ha acompañado de una introducción general a modo de balance.

- Breve descripción en aquellos casos en los que el título no sea orientativo del contenido.

La clasificación utilizada para distribuir los recursos ha sido la siguiente:

- Directorios y guías de recursos españoles e internacionales

- Bases de datos bibliográficas

- Bibliotecas y centros de documentación españoles e internacionales

- Organismos de la administración supranacional, española y de otros países

- Asociaciones de defensa del patrimonio y profesionales

- Imágenes de arquitectura

- Formación: instituciones y cursos de nivel nacional e internacional

- Investigación: centros de investigación y grupos de investigación

- Publicaciones: revistas especializadas, revistas electrónicas, textos y diccionarios

- Librerías y editoriales

- Listas de distribución

\section{Directorios y guías de recursos}

En la red podemos encontrar de todo, $y$ podemos navegar y pasarnos las horas de servidor en servidor de una punta a otra del mundo viendo información "curiosa". El problema aparece cuando el uso que deseamos realizar es de tipo profesional: En ese caso necesitamos acceder a información fiable, nuestro tiempo es muy valioso y no podemos perderlo haciendo un rastreo exhaustivo de un enorme listado lleno de "ruido" extraído de un buscador con millones de registros catalogados la mayoría de las veces sin criterios rigurosos y donde, además, es muy probable que no esté lo que buscamos.

Por tanto, y aunque siempre podemos navegar en función de nuestras estrictas necesidades dando nuestro personal "golpe de timón", es mejor acudir a la experiencia de profesionales -ya sean arquitectos, gestores del patrimonio o documentalistas- que ya han investigado sobre recursos en la Red de forma especializada, para encontrar de manera rápida y segura la información que necesitamos.

No es sencillo, entre la abundancia de enlaces denominados "otros webs de interés", "links" o "websites" que nos ofrecen algunas páginas, seleccionar recopilaciones de recursos que sean interesantes, pues a veces se trata casi de "marcadores" (bookmarks) o agendas personales con contenido muy heterogéneo. Para seleccionar las guías más útiles se pueden aplicar los siguientes criterios: cantidad y calidad de las direcciones que proporcionan, exhaustividad o buena cobertura en el campo de interés del que se trate, inclusión de una descripción o comentario sobre el recurso incluido en la guía, buena organización de las direcciones, posibilidad de realizar búsquedas en el directorio, actualización y buen funcionamiento de los enlaces, y visibilidad de las direcciones URL. También, en lo que concierne al patrimonio, se pueden valorar las guías en función de la proximidad geográfica y cultural de los recursos que incluyen.

Se podría pensar que acudiendo a las páginas de instituciones muy importantes en el ámbito del patrimonio arquitectónico se encontrarán buenos directorios, pero generalmente no es así. Sin embargo conviene prestar atención a estas páginas y a muchos "websites" que se están construyendo actualmente, pues pueden incluir buenos directorios en el futuro.

No existen grandes directorios especializados en exclusiva en patrimonio arquitectónico, por lo que es necesario acudir a guías de recursos especializadas en patrimonio cultural en general, guías especializadas en arquitectura y, aunque de menor interés en general, directorios especializados en arte.

España

- Webs de Interés del IAPH (Instituto Andaluz de Patrimonio Histórico de la Junta de Andalucía)

http://www.iaph.junta-andalucia. es/webs.html

- Guía del Departamento de Construcciones Arquitectónicas de la Universidad Politécnica de Cataluña

http://www.upc.es/ca1/webguia.html

- La ArchiWeb. de Antonio Nievas Temas de Arquitectura

http://www.nsi.es/personal/anievas/arquitectura.html

- Sólo Arquitectura. Servidor de información dirigido a arquitectos

http://www.soloarquitectura.com/

- Webconstructivas. Webs de interés del ICCE (Instituciones Colegiales para la Calidad en la Edificación).

http://www.icce.es/icce/webfavoritas.htm

Internacionales y otros países

- Patrimoine

http://www.culture.fr/culture/autserv/patrimoi.htm

Compilación de recursos sobre patrimonio en Internet del Ministerio de Cultura de Francia 
- Internet Heritage Resources. http://www.sphpc.org/other/resource.htm Recursos de patrimonio y conservación en Internet de la "Southwestern Pennsylvania Preservation Commission.

- NCPTT : Preservation Internet Resources http://www.ncptt.nps.gov/prog_pir_fs.stm Guía de recursos del National Center for Preservation Technology and Training

- Heritage Conservation and Historic Preservation. State Library of Victoria.

http://home.vicnet.net.au/ conserv/hphc.htm

Guía de recursos sobre patrimonio de la Biblioteca estatal de Victoria (Australia).

- Cyburbia: Internet Resources for the Built Environment http://cyburbia.ap.buffalo.edu/

- Architecture Web Resources. http://www.nscee.edu/

Guía de recursos en arquitectura y construcción de Jeanne Brown.

- Virtual Library: Architecture. Universidad de Toronto

http://www.clr.toronto.edu:I080/VLA.html

- ADAM (Art, Design, Architecture \& Media Information Gateway)

http://adam.ac.uk/adam/

- Guía de recursos en Internet especializada en arquitectura elaborada por los alumnos del Instituto Universitario de Arquitectura de Venecia.

http://cidoc.iuav.unive.it/architettura/archweb.ope/homenuova.html

- Architectural Index of Sites http://www.plannet.com/indexdt.html

- Yahoo. Arts

http://dir.yahoo.com/arts/

\section{- ArtSource}

http://www.ilpi.com/artsource/artsourcehome.html

Recursos sobre Arte y Arquitectura de las Bibliotecas de la Universidad de Kentucky

- Fine Arts Library: Architecture Resources.
Biblioteca de la University of British Columbia

http://www.library.ubc.ca/finearts/ARCHITECTURE.html

- Art History Resources del Sweet Briar College (Virginia).

http://witcombe.sbc.edu/ARTHLinks4.html

\section{Bases de datos bibliográficas}

La mayoría de las bases de datos con información referencial bibliográfica se crearon en la década de los años 1970 y acumulan en la actualidad una gran cantidad de información. Mucho antes de la creación de Internet la mayor parte de ellas eran consultables en línea por vía telefónica. Se crearon entonces grandes distribuidores de bases de datos que permitían acceder a distintas bases de datos mediante un lenguaje de consulta común. Dichos distribuidores tienen actualmente sus sitios web en Internet y distribuyen sus bases de datos en la red.

La situación, en cuanto a las bases de datos que interesan para el patrimonio arquitectónico, es variopinta: se encuentran en Internet desde algunas bases de datos de acceso público que podemos consultar gratuitamente hasta otras para las que hay acceso restringido o hay que solicitar clave de usuario y pagar por la misma. También hay otras situaciones intermedias. En general no se produce un problema de acceso a la información para el usuario final, ya que las grandes bibliotecas $y$ centros de documentación especializados suelen estar abonados a los grandes distribuidores de información. Por otra parte, aunque el usuario pueda acceder a la información, es frecuente que las bibliotecas y centros de documentación especializados repercutan el precio de las consultas a las bases de datos de pago en los usuarios. Además, algunas bases de datos bibliográficas ofrecen servicios complementarios de acceso al documento original.
Aunque ya se ha señalado que no es una novedad poder consultar en línea esta información, las ventajas de Internet con respecto a la modalidad de acceso anterior son notables, puesto que las búsquedas de información se venían delegando tradicionalmente en expertos documentalistas que actuaban como intermediarios, mientras que en la actualidad, con Internet, los diseños de las pantallas de consulta son mucho más amigables y los usuarios finales, generalmente familiarizados con las utilidades de Internet, pueden buscar directamente la información de su interés. Se han seleccionado doce direcciones mediante las cuales se accede en Internet a bases de datos bibliográficas especializadas, de las cuales cuatro son de grandes distribuidores de información.

- $\mathrm{CHIN}$ : Conservation Information Network. Bibliographic Database (BCIN)

http://www.chin.gc.ca/Resources/Research_Ref/Reference_Info/BCIN/e_hp_bcin. html

- VictorWeb: Catalogs and Databases. http://victorweb.lib.umd.edu:9000/ Catálogos y Bases de datos de "National Trust for Historic Preservation Library Collection", de la Universidad de Maryland. Incluye la base de datos de artículos de revistas NTL Index.

\section{- Getty Databases \\ http://www.getty.edu/}

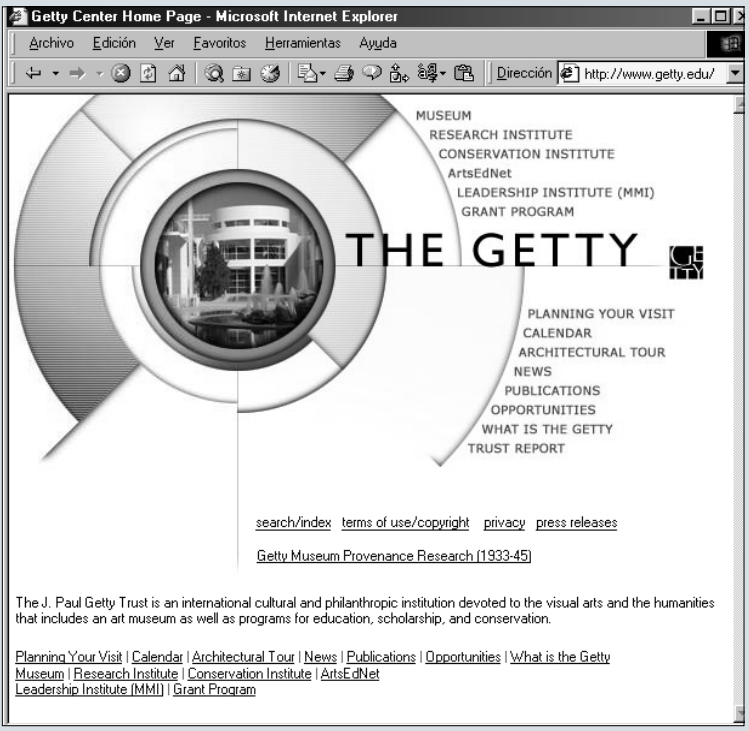


- DialogWeb

http://www.dialogweb.com/servlet/logon? Mode $=1$

Dialog gestiona más de 450 bases de datos diferentes de muy diversas disciplinas

- EINS

http://www.eins.org/

Web de European Informatión Network Services

- FIZ Karlsruhe and STN Internationa: Databases in Science and Technology http://www.fiz-karlsruhe.de/

- $\operatorname{archINFORM}$ http://www.archinform.de/

ArchINFORM es una base de datos realizada en Alemania: tiene su sede en Postdam y su sitio web les ha sido proporcionado por la Universidad de Karlsruhe Es una base de datos de arquitectura cuyo origen son los registros de proyectos de edificación interesantes para los estudiantes de arquitectura. No obstante se ha convertido en la base de datos más amplia en arquitectura internacional. Incluye unos 8000 proyectos (realizados o no) de diferentes arquitectos y urbanistas.

\section{- UNESBIB}

http://unesdoc.unesco.org/ulis/unesbib.html Bibliografía de los documentos, publicaciones y fondos bibliográficos de la Unesco. Desde el mismo servidor se puede acceder a UNESDOC, base de datos con los documentos de la UNESCO en texto completo.

- Bases de datos del CINDOC (Centro de Información y Documentación Científica del CSIC) http://www.cindoc.csic.es/prod/bases.htm

- Biblioteca i Arxiu Històric d'arquitectura del Colegio oficial de arquitectos de Cataluña http://www.coac.es/COAC/centre_documentacio/COAC_e.html

- ARCAT

http://www.iec.es/cat/recerca/programes/ his toricoarqueologica/arcatcat.htm

Base de datos de arquitectura románica catalana elaborada por el Institut d'Estudis Catalans.

\section{Bibliotecas y Centros de Documentación}

Los OPAC (catálogos públicos de acceso en línea) de las bibliotecas, son uno de los recursos que aparecieron pronto en Internet. Se accede a ellos mayoritariamente por un telnet, pero el acceso vía web está cada vez más extendido y se pueden consultar sin necesidad de intermediarios. Existen distintos módulos OPAC según diferentes programas informáticos disponibles. Estos programas no están diseñados como simples sistemas de recuperación de la información, sino como módulos que forman parte de un sistema integrado de gestión de bibliotecas. Aunque los programas son diferentes, la mayoría funciona por menús que van indicando al usuario las órdenes para realizar una búsqueda. También suelen tener pantallas de ayuda de forma que se puede realizar una consulta sin necesidad de acudir al bibliotecario.

Los OPACs son uno de los recursos de información más importantes de la red. Además de incluir las direcciones de los principales catálogos españoles de este tipo, que pueden proporcionar abundante información sobre fondos bibliográficos relativos al patrimonio, y una selección de los catálogos del resto del mundo, se han incluido en este apartado directorios de bibliotecas, páginas web de bibliotecas especializadas -tengan o no acceso en línea al catálogo- y también algunos sitios web de centros de documentación especializados -de los cuales algunos tienen bases de datos de elaboración propia- debido al interés que puede tener la descripción de sus fondos y de los servicios que prestan.

\section{España}

\section{- Bibliotecas Españolas}

http://www.uv.es/biblios/webs/web_Espa.html

- Bibliotecas de Arte de España y Portugal http://www.mcu.es/BAEP/

- Biblioteca Nacional de España http://www.bne.es/

- REBIUN: Red de Bibliotecas Universitarias Españolas http://www2.uji.es/rebiun/
- RUECA: Red Universitaria Española de Catálogos Absys

http://www.baratz.es/cgi-bin/abwebr

- RUEDO: Red Universitaria Española DOBIS/LIBIS

http://www.uned.es/bibliote/biblio/ruedo.htm

- Red de Bibliotecas del CSIC

http://www.csic.es/cbic/cbic.htm

\section{- Catálogos CIRBIC} http://www.csic.es/cbic/acceso.htm

Catálogos informatizados de la Red de Bibliotecas del CSIC

- Catàleg Col·lectiu de les Universitats de Catalunya

http://www.cbuc.es/ccuc/

- Sistema de Xestion de Bibliotecas de Galicia http://biblio.cesga.es/screens/opacmenu_ gag.html

- Biblioteca de Instituto Cervantes http://www.cervantes.es/internet/biblioteca/mar_biblio.htm

- Biblioteca del CINDOC

http://www.cindoc.csic.es/servicios/biblioteca_principal.html

- Biblioteca de Arquitectura de la Universidad de Sevilla

http://arqui4.us.es/bib/biblioteca.html

- E.T.S. Arquitectura de Madrid con enlace a la biblioteca

http://www.aq.upm.es/

- Biblioteca de la ETS de Arquitectura de Las Palmas

http://www.cda.ulpgc.es/biblio.html

- Biblioteca de la ETS de Arquitectura de Barcelona

http://escher.upc.es/bib210/b210_cs.htm

- Centro de Documentación de Arquitectura del Colegio de Arquitectos de Andalucía Oriental http://www.arquired.es/coaao/cda/

- Biblioteca i Arxiu Hitòric d'Arquitectura Colegio de Arquitectos de Cataluña 
http://www.coac.es/COAC/centre_documentacio/Biblioteca_COAC/default_c.html

- Biblioteca del Colegio de Aparejadores y Arquitectos Técnicos de Alicante http://www.icce.es/gt.alicante/bibliot.htm

- Centre de Documentación del Colegio de Arquitectos Técnicos de Barcelona Josep Renart

http://www.apabcn.es/tecnica/renart/centre2.htm

- Biblioteca de la Real Academia de Bellas Artes de San Carlos http://aras.arq.upv.es/princi/equipa/2127.htm

\section{- Museo Arqueológico Nacional}

http://www.man.es/

Las bibliotecas de museos y algunas bibliotecas españolas especializadas en arte, como la de la Academia de Bellas Artes de San Fernando, no tienen de momento página web o la que tienen no da acceso a sus catálogos. El Instituto Español de Patrimonio Histórico no tiene actualmente web institucional ni de la biblioteca.

\section{Internacional y otros países}

\section{DIRECTORIOS DE BIBLIOTECAS}

- Bibliotecas nacionales del mundo http://exlibris.usal.es/bibesp/nacion/index.htm

- National Libraries of Europe http://portico.bl.uk/gabriel/en/eurocoun.html

- Association of Architecture School Librarians http://libraries.mit.edu/rotch/architecture/ aasl-dir.html

- IFLA: Section of Art Libraries International. Directory of Art Libraries http://iberia.vassar.edu/ifla-idal/

- Architecture. Directorio de Centros de Documentación y Bibliotecas. (Francia) http://www.culture.fr/culture/sedocum/ archi.htm

- Catalogues de bibliothèques francophones Bibliothèques arts http://www.abf.asso.fr/sitebib/f_bibcat.htm

\section{GRANDES CATÁLOGOS COLECTIVOS}

- COPAC: University Research Library Catalogue (Reino Unido)

http://copac.ac.uk/copac/

- Iccu. Catálogo del Istituto Centrale per i Catálogo Unico (Italia) http://opac.sbn.it/

\section{BIBLIOTECAS ESPECIALIZADAS}

- National Trust Library for Historic Preservation Library Collection http://www.lib.umd.edu/

- ICCROM Library http://library.iccrom.org/index.html/

- ICOMOS. Centro de Documentación UNESCO-ICOMOS

http://www.international.icomos.org/icomos/f_doc.htm

- Centro de documentación de la Unión Internacional de Arquitectos

http://www.ctav.es/cuiap/uia_sp.htm

- Docomomo (Organización Internacional para la Documentación y Conservación del Movimiento Moderno) http://www.ooo.nl/docomomo/home.htm

- Médiathèque de I'Architecture et du Patrimoine (Francia)

http://www.culture.fr/culture/sedocum/ patri-b.htm

- Bibliothèque du Musée des plans-reliefs (Francia)

http://www.culture.fr/culture/sedocum/ mplr-b.htm

- Centre de documentation du Laboratoire de Recherche des Monuments Historiques (LRMH)

http://www.culture.fr/culture/sedocum/ Irmh-cd.htm

- Centre de Documentation de l'École Nationale du Patrimoine (Francia)

http://www.culture.fr/culture/sedocum/ enp-cd.htm

- Computer Catalogue-National Art Library http://www.nal.vam.ac.uk/nalcomct.html

- Bibliothèque du CCA (Centro Canadiense de Arquitectura)

http://cca.qc.ca/New_Site/library/library_ new_fr.html

- MIT: Rotch Library of Architecture and Planning http://libraries.mit.edu/rotch/

- Médiathèque d'IAURIF (Francia) http://www.iaurif.org/projet/fr_media.html

- EAG: Centro de Documentación de la Escuela de Arquitectura de Grenoble http://www.grenoble.archi.fr/pyramide/ cdi.htm

- Istituto Universitario di Architettura di Venezia. Servizi bibliografici e documentali http://iuavbc.iuav.unive.it/

- RIBA Library: Biblioteca del Royal Institute of British Architects http://st I 2.yahoo.net/riba-library/

\section{Organismos de la Administración}

Los organismos encargados de la protección del patrimonio utilizan sus sitios web para darse a conocer, pero además ofrecen un recurso de información de gran importancia: las listas, los registros o los inventarios del patrimonio. Estos son instrumentos de protección jurídico-administrativa del patrimonio incluido en ellos al tiempo que fuente para la documentación del mismo. La aparición de inventarios de edificios y sitios históricos en la red es la aportación más interesante que los organismos de protección del patrimonio ofrecen como recurso en Internet. No obstante, este uso de la red supone una importante inversión debido a la información gráfica que suelen proporcionar, siendo sólo entidades nacionales o regionales, con un importante presupuesto quienes pueden hacer frente a este desembolso. Por otro lado cada base de datos de este tipo tiene una información distinta, estructurada de diferente forma y unos parámetros de consultan que varían de una a otra. Todo ellos es el resultado de la herencia de los inventarios tradicionales, que reflejan culturas y modos de hacer distintos, y marcos jurídico-administrativos diferentes. 
Se han incluido 46 direcciones de páginas de este tipo de organismos, 12 son españolas y pertenecen todas a la administración. Entre las de los países del ámbito anglosajón, y en el caso de alguna organización supranacional, se encuentran algunas direcciones web que no pertenecen a la administración. Esto es debido a la distinta tradición en cuanto a la protección del patrimonio. En los países de ese ámbito muchas entidades privadas sin ánimo de lucro han sido o son protagonistas en la protección del patrimonio cultural.

España

- INMU

http://www.mcu.es/bases/spa/inmu/INMU. html

La Dirección General de Bellas Artes, de la Secretaría de Estado de Cultura (Ministerio de Educación y Cultura) proporciona acceso desde sus páginas web a la Base de datos de Bienes de Interés Cultural Inmuebles (INMU).

- Instituto Andaluz de Patrimonio Histórico (IAPH), de la Junta de Andalucía

http://www.iaph.junta-andalucia.es/

- Dirección General de Patrimonio Artístico de la Generalitat Valenciana

http://www.cult.gva.es/dgpa/

- Patrimonio de Cantabria

http://www.cultura- cantabria.org/cultu ra/patrimonio/index.htm

- Junta de Comunidades de Castilla-La Mancha. Patrimonio

http://www.jccm.es/turismo/patrimonio/ind ex.htm

- Dirección Xeral de Patrimonio Cultural de la Conselleria de Cultura de la Xunta de Galizia http://www.xunta.es/conselle/cultura/home /cultura3b.htm

- Dirección General de Patrimonio Histórico de Canarias

http://www.funpatri.com/fphcyll.htm

Para concluir con la información relativa a las comunidades autónomas nos referiremos a Cataluña, comunidad que ha desarrollado nor- mas y niveles particulares de protección pero que todavía no tiene unas páginas web dedicadas a patrimonio. Sin embargo los responsables de patrimonio están proyectando un "website" en el cual, además de dar acceso a las bases de datos tipo inventario, darán a los usuarios la oportunidad de rellenar un formulario de solicitud de incoación de expediente para bienes no protegidos.

- Casa de S.M. el Rey de España - Palacios y Reales Sitios

http://www.casareal.es/casareal/cast/palacios.html

- Patrimonio histórico cultural del CSIC http://www.csic.es/hispano/patrimo/patrimo2.htm

- Ciudades Patrimonio de la Humanidad http://www.cyberspain.com/ciudades-patrimonio/

- Toledo: Patrimonio de la Humanidad http://www.uclm.es/vic-to/a_I.htm

- World Heritage in Spain http://www.spaintour.com/heritage.htm

Internacional, supranacional y otros países

- WHC CONVENTION http://www.unesco.org/whc/nwhc/pages/ $\mathrm{doc} /$ main.htm

- World Heritage Information Network http://www.unesco.org/whin/frindex.htm El Centro de Patrimonio Mundial de la UNESCO es el secretariado para la Convención relativa a la protección del patrimonio cultural y natural mundial. El gopher y el servidor www incluyen el texto de la Convención del Patrimonio Mundial, líneas generales de funcionamiento, la Lista del Patrimonio Mundial y la lista del patrimonio en peligro.

- ICOMOS International Council on Monuments and Sites http://www.icomos.org/

- ICOMOS Spanish Committee http://www.icomos.org/espana/

- ICCROM (International Centre for the Study of the Preservation and Restoration of Cultural Property)

http://www.iccrom.org/

- World Monuments Fund

http://www.worldmonuments.org/

\section{- European Heritage. Proyecto HEREIN} http://www.european-heritage.net/ HEREIN (Información sobre el patrimonio europeo) es la denominación de un proyecto del Consejo de Europa que consiste en la creación de un "web site" que servirá como red europea de información sobre las políticas de patrimonio. Se trata, por tanto, de un web en construcción cuyas páginas van a estar dedicadas a servir para la difusión y el intercambio de información sobre las políticas nacionales de patrimonio que se realizan en los paises miembros del Consejo de Europa, siguiendo las recomendaciones de la Conferencia de Helsinki.

Se incluyen a continuación otras tres direcciones, dentro del servidor del Ministerio de Cultura francés, en las que podemos encontrar textos interesantes sobre políticas de patrimonio en Europa, todos ellos relacionados también con el Consejo de Europa.

- ECC: Patrimoine culturel. Analyse des politiques nationales http://culture.coe.fr/pat/fr/homepage_pol.htm

- ECC: Patrimoine culturel. Rapport sur les politiques du patrimoine - Espagne http://culture.coe.fr/pat/fr/9694frev..htm

- ECC : 4ème Conférence des Ministres responsables du patrimoine culturel. http://culture.coe.fr/infocentre/txt/fr/fconfer4.htm

- IM Europe: Servidor de la Unión Europea sobre el sector público en la sociedad de la información

http://www.echo.lu/

- Directorate General XIII: Information Society: Telecommunications, Markets, Technologies. Innovation and Exploitation of Research.

http://europa.eu.int/comm/dg / 3/index.htm El servidor de la Dirección General XIII, Sociedad de la Información, es muy interesante debido a la información que suminis- 
tra acerca de los proyectos relacionados con la digitalización de imágenes y los productos multimedia, muchos de ellos relacionados con patrimonio.

- Trading Cultural Assets. Projects http://www2.echo.lu/milia98/projects.html En este apartado del servidor l'm Europe, que se podría traducir como "Explotación del patrimonio cultural" se incluyen, además de los proyectos directamente relacionados con patrimonio arquitectónico, algunos relacionados con imágenes (digitalizacion, propiedad, etc), con museos y con desarrollo del turismo.

\section{- CICERO}

http://www.tweuro.com/tura/tourism/html /cicero.html

El proyecto CICERO es un ejemplo, entre los proyectos incluidos en la dirección URL anteriormente comentada.

- EPIC: European Preservation Information Center

\section{http://www.knaw.nl/ecpa/}

- Localizador Internet del Patrimonio europeo http://eur-heritage.com/index.htm

- Le Ministère de la culture et de la communication (Francia) http://www.culture.fr/

\section{- Merimee}

http://www.culture.fr/documentation/merimee/accueil.htm

Es una base de datos que incluye el patrimonio monumental francés en toda su diversidad: arquitectura religiosa, doméstica, agrícola, escolar, militar e industrial desde el siglo IV a 1950.

\section{- Base Mil-XXe}

http://www.culture.fr/cgibin/wave.cgi?dqi= mil- $x x \& i c o n=/ d o c u m e n$ tation/icones

Desarrollada por el Inventario General, esta base de datos contiene información sobre unos mil inmuebles del siglo $\mathrm{XX}$ protegidos.

- CNMHS: Caisse National des Monuments Historiques et des Sites

http://www.monuments-france.fr/

- Portugal. Direcçao Geral dos Edificios e Monumentos Nacionais http://www.monumentos.pt/
- English Heritage

http://www.english-heritage.org.uk/

- Royal Commission on the Historical Monuments of England

http://www.coi.gov.uk/coi/depts/GHM/GH M98QI.html

Comisiones semejantes con páginas web existen en Escocia y Gales, pero no se han incluido aquí porque no ha podido ser visitado el servidor. Otro tanto ha sucedido con "The Architectural Heritage Society of Scotland", la organización sin ánimo de lucro "Glasgow West Conservation Trust", etc. Todas estas instituciones aparecen en las guías de recursos que se han proporcionado.

Respecto a Italia, no se ha podido conectar con el web de la Agenzia per i Beni Artistici e Cultural, ni con el mapa del Riesgo del Patrimonio Cultural en Italia, cuya dirección aparece en muchas guías de recursos. El sitio web del Ministerio para los Bienes Culturales de Italia no ofrece por el momento información relevante, por lo que se incluiye una dirección de un servicio que funcionalmente depende del ministerio y contiene una información distinta a la que suelen ofrecer los servicios oficiales de patrimonio:

\section{- Comando Carabinieri Tutela Patrimonio Artistico}

http://www.beniculturali.it/cctpa/storial.html

- Suiza-Banque de données des biens culturels suisses

http://www.dsk.ch/html/bdbs.htm

- Consejo de Monumentos de Chile

http://www.monumentos.cl/

- Monumentos Historicos Nacionales Argentinos http://www.monumentos.org.ar/

- Canadian Heritage Information Network (CHIN)

\section{http://www.chin.gc.ca/}

- Heritage Foundation of Newfoundland and Labrador

http://www.avalon.nf.ca/heritage/

- Biens culturels protégés (Canadá) http://www.synapse.net/ outaouais/batiment.htm

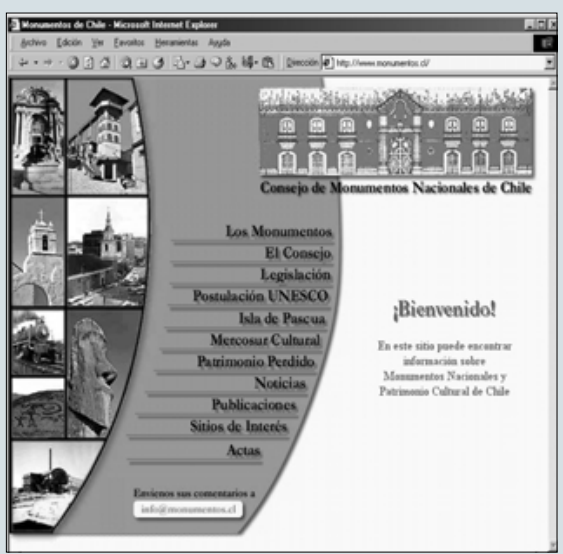

- Répertoire des biens culturels et arrondissements du Québec

http://www.mcc.gouv.qc.ca/pamu/biensculturels/index.htm

- African Heritage Architecture http://www.africanarchitecture.com/index. shtml

En cuanto al panorama en los Estados Unidos y Australia hay, sobre todo en el primero, multitud de direcciones web de entidades, dependientes de instituciones públicas o de instituciones privadas, relacionadas con el patrimonio. Entre ellas destacan las del "National Center for Preservation Technology an Training" y "National Trust for Historic Preservation" en Estados Unidos y "Australia World Heritage Areas". La mayoría de las guías de recursos recomendadas recogen exhaustivamente las direcciones de organizaciones pertenecientes a estos países.

\section{Asociaciones}

Las páginas de las asociaciones generalmente se limitan a presentar sus objetivos, ofrecer datos sobre sus asociados y proporcionar información acerca de sus actividades. Se presentan aquí 28 direcciones web entre las cuales se incluyen dos tipos principales de asociaciones: las asociaciones para la defensa del patrimonio arquitectónico y las asociaciones de profesionales relacionados con el patrimonio arquitectónico. Entre las primeras se incluyen tanto las asociaciones de ámbito supranacional como las de ámbito nacional así como, para el ámbito español, las páginas de algunas 


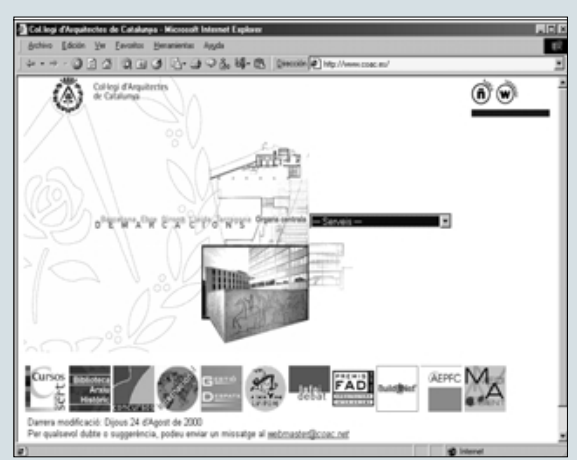

fundaciones o entidades sin ánimo de lucro con objetivos parecidos en cuanto a la defensa del patrimonio. Entre las asociaciones profesionales incluimos las de conservadores, restauradores, historiadores de la arquitectura y arquitectos.

\section{Asociaciones de defensa del patrimonio}

- OWHC: Organization of World Heritage Cities

http://www.ovpm.org/

- Save Britain's Heritage

http://www.savebritainsheritage.org/main. htm

- Europa Nostra

http://www.catharina-collet.dk/page2.htm

- Italia Nostra

http://www.alfanet.it/welcomeltaly/ItaliaNostra/indice

- Patrimoine et Paysages. Federación nacional francesa de las asociaciones de salvaguarda de sitios y conjuntos monumentales.

http://www.patrimoine-et-paysages.org/

- PREMAAT e Hispania Nostra juntos en la conservación del Patrimonio

http://www.premaat.es/hispanianostra.htm

- Fundación del Patrimonio de Castilla y León http://www.funpatri.com/fphcyll.htm

- Departamento de Patrimonio Cultural de la Fundación La Caixa

http://www.fundacio.lacaixa.es/cas/ambits/a rts/historia.htm
- Fundación Caja Rioja: Itinerarios Culturales y Rutas Temáticas

http://www.fundacion-cajarioja.es/actas.htm

- CIMBRA: Asociación de estudiantes interesados por el patrimonio

http://www.arq.upv.es/cimbra/

- Forum UNESCO Universidad y Patrimonio http://forumunesco.upv.es/

Desde la página principal de este web (que es el de Forum Unesco: Red de cooperación universitaria para la salvaguarda del patrimonio) se puede acceder a la información de la Asociación de Estudiantes para la Defensa del Patrimonio (AEDP)

\section{Asociaciones de profesionales}

- APT: Association for Preservation Technology

http://www.apti.org/

- CAC/ACCR: Association Canadienne pour la conservation et la restauration http://www.cac-accr.ca/

- Society of Architectural Historians http://www.sah.org/

- UIA: Union International des Architectes http://www.uia-architectes.org/countuia.shtml

- AIAOnline-American Institute of Architectes http://www.aiaonline.com/

- Ribanet-Royal Institute of British Architects http://st9.yahoo.net/riba-net/

En cuanto a las asociaciones profesionales españolas no hay de momento páginas de asociaciones de conservadores, restauradores o historiadores de la arquitectura, pero si se encuentran en Internet los colegios profesionales de arquitectos. En sus sitios web proporcionan una presentación más o menos completa de la asociación: organización interna, información sobre los colegiados, y sobre los cargos directivos, servicios que presta el colegio, etc. Algunos también incluyen información sobre sus publicaciones y actividades -cursos, conferencias, exposiciones o concursos-. El Consejo Superior de los colegios de arquitec- tos de España incluye en sus páginas web una definición de la normativa deontológica de la profesión. Entre el conjunto de los sitios web de colegios de arquitectos, además de aquellos que tienen bibliotecas o centros de documentación importantes, destacan el del Colegio Oficial de Arquitectos de Andalucía Occidental, con información sobre FIDAS (Fundación para la Investigación y Difusión de la Arquitectura) y el del Col.legi d'Arquitectes de Catalunya, con muy buen contenido y con un enlace a su centro de documentación.

- Consejo Superior de los Colegios de Arquitectos de España

http://www.arquinex.es/consejo/HomePage.htm

- Colegio Oficial de Arquitectos de Madrid http://www.coam.es/

- Col.legi d'Arquitectes de Catalunya

http://www.coac.es/

- Virtual COAB: Collegi oficial d'arquitectes de Balears

http://www.coab.es/

- Colegio oficial de arquitectos de la Comunidad Valenciana

http://195.76.117.3/

- Colegio de Arquitectos de Canarias

http://www.arquired.es/Canarias/

- COAG

http://www.coag.es/

- Colegio Oficial de Arquitectos de Andalucía Occidental

http://www.arquired.es/Profesion/COAAO/

- Colegio oficial de arquitectos de Andalucía Oriental

http://www.arquired.es/Profesion/COAAOR/

- Colegio de Arquitectos de Alicante http://www.ctaa.net/

\section{Imágenes de arquitectura}

Las imágenes del patrimonio arquitectónico son un recurso de información interesante tanto por el uso que de ellas pueden hacer los profe- 
sionales como por su utilidad para la difusión de este patrimonio entre el gran público. El web tiene, en comparación con soportes fijos que se utilizan para la edición de productos multimedia sobre el patrimonio arquitectónico como el CD-ROM o el DVD, poca capacidad y acusada lentitud para la transmisión de las imágenes digitalizadas pero, aunque no se puede usar con resultados aceptables para imágenes en movimiento, el web se utiliza para difundir imágenes fijas y es un soporte más flexible y con mayor vitalidad que los soportes fijos mencionados.

Se incluyen a continuación recursos visuales sobre patrimonio arquitectónico de tipo muy variado, con el fin de dar una idea de los distintos tipos de sitios web o bases de datos presentes en Internet que ofrece imágenes como principal recurso de información: desde simples catálogos que sólo referencian imágenes hasta verdaderos bancos de imágenes que se pueden visualizar en la red, pasando por modestos proyectos o pequeñas colecciones de imágenes digitalizadas. Se tratarán: Los catálogos de fototecas consultables via web, que pueden incluir o no las imágenes que referencian y pueden estar especializados en imágenes de arquitectura $\mathrm{O}$, sin estar especializados, incluir recursos visuales sobre el patrimonio arquitectónico; Las bases de datos o páginas web con imágenes de arquitectura digitalizadas concebidas expresamente para su divulgación en Internet y Los catálogos de colecciones de dibujos o grabados, estén especializados o no en dibujo o grabado arquitectónico. También pueden ser de interés, aunque secundario, para el profesional relacionado con el patrimonio arquitectónico los catálogos de las colecciones de los museos que incluyen imágenes y otro tipo de recursos web que habitualmente las inlcuyen como, por ejemplo, las páginas dedicadas a divulgar el patrimonio.

- University of Arizona. Image Projects http://www.library.arizona.edu/images/image_projects.html

- Biblioteca nacional de España. Catálogo de grabados dibujos y fotografías

http://www.bne.es/cgibin/wsirtex?FOR=WI UBINP4\&VIS=W05BINP

- Centre de Recherche des Monuments historiques (CRMH) (Francia)

http://www.culture.fr/culture/sedocum/cr mnh.htm
- Base Mémoire. Catálogo de imágenes fijas común para los servicios del Inventario General y de la Mediateca de arquitectura y patrimonio de Francia.

http://www.culture.fr/cgibin/wave.cgi?dqi= memoire\&icon=/docu mentation/icones

- $\mathrm{S} * \mathrm{P} * \mathrm{I} * \mathrm{R} * \mathrm{O}$ : Base de datos de imágenes de arquitectura de la Universidad de California

http://www.mip.berkeley.edu/query_forms/ browse_spiro_form.html

- Digital Media Center. Imágenes digitalizadas sobre la Historia de la Arquitectura http://www.lib.virginia.edu/dmc/

\section{- Quondam: Museo virtual de arquitectura} http://www.quondam.com/

- Renaissance and Baroque Architecture. Colección de imágenes http://www.lib.virginia.edu/dic/colls/arh l02/ index.html

- Thais: Imágenes de 40 siglos de Historia de la Arquitectura

http://www.thais.it/

- California Heritage Collection. 28000 imágenes de la historia y cultura de California http://sunsite.Berkeley.EDU/CalHeritage/

- Palladio Museum http://andrea.gsd.harvard.edu/palladio/

Sitio web de la Universidad de Harvard con imágenes de 43 obras de Andrea Palladio, texto completo de sus "Cuatro libros de arquitectura" y texto de la obra de $\mathrm{O}$. Bertotti Scamozzi sobre Palladio.

\section{- ANU Art History Top Level} http://rubens.anu.edu.au/

- ArtServe. Images of architecture of the Mediterranean Basin

https://rubens.anu.edu.au/architectureindex.html

- Cities/Buildings Image Archive https://www.washington.edu/ark2/

- Digital Archive of European Architecture http://www.bc.edu/bc_org/avp/cas/fnart/arc h/default.html
- AcIS/CUL Imaging and Hypertext Projects http://www.columbia.edu/imaging/html/ima ging.html

\section{- Collections Database}

http://www.whitworth.man.ac.uk//collections.html

Es la base de datos de la colección de acuarelas, dibujos y grabados más conocida del Reino Unido: la de la Whitworth Art Gallery.

- SCRAN

http://www.scran.ac.uk/

- Sistemas de Información del CSIC. Fototeca de Historia del Arte

http://www.bdcsic.csic.es:8080/fototeca/

- Champollion. Colecciones de arte egipcio de los museos europeos

http://www.ccer.nl/champollion/

- Survey European Photographic Collections http://www.knaw.nl/ecpa/form.htm

\section{Formación}

En el terreno de la formación, aunque las universidades fueron pioneras en estar presentes en Internet y ofrecer información general sobre sus organizaciones, lo cierto es que cuando se busca información detallada sobre determinados aspectos, tal es el caso de los cursos de postgrado, es muy difícil encontrarla. Lo ideal sería contar con directorios de cursos e instituciones especializadas en la organización de cursos sobre patrimonio en general y arquitectónico en particular. A nivel internacional el ICCROM en colaboración con el Instituto de Conservación Getty elabora uno de estos directorios con bastante información y de uso sencillo y práctico. Sin embargo, no existe nada similar a nivel nacional, con lo que la localización de instituciones y cursos se convierte en una búsqueda laboriosa y difícil. La única institución que alivia esta búsqueda en España es el Centro de Documentación en Arquitectura del Colegio Oficial de Arquitectos de Andalucía Occidental que reúne en uno de los apartados de su web una recopilación de cursos, congresos, seminarios y masters relacionados con el mundo de la arquitectura. 


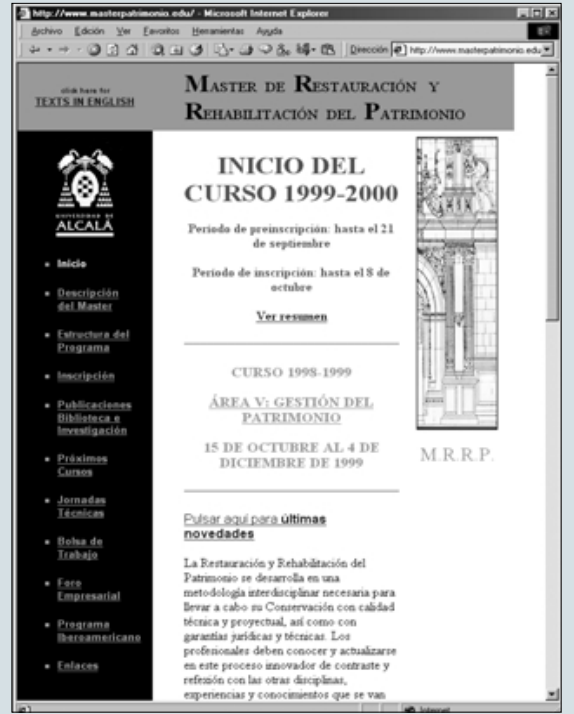

\section{Instituciones}

- Centro de Formación IAPH (España) http://www.iaph.junta-andalucia.es/formacion.html

- School of Conservation Sciences. Bournemouth University (Reino Unido)

http://csweb.bournemouth.ac.uk/consci/tex t/index.htm

- School of Resource, Environmental and Heritage Sciences (Australia)

http://science.canberra.edu.au/rehs/home.htm

- The Ironbridge Institute (Reino Unido) http://www.bham.ac.uk/IRONBRIDGE/

- Institute of Historic Buildings Conservation (Reino Unido)

http://www.ihbc.org.uk/

- Ecole Nationale du Patrimoine (Francia) http://www.culture.fr/culture/enp.htm

- Universty of Vermont. Historic Preservation Program (Estados Unidos)

http://www.uvm.edu/ histpres/uvmhp.html

- University of Oregon Historic. Preservation Program. (Estados Unidos)

http://laz.uoregon.edu/ histpres/index.html

- University of Victoria. Cultural Resource Management Program (Canadá)

http://www.uvcs.uvic.ca/crmp/welcome.htm

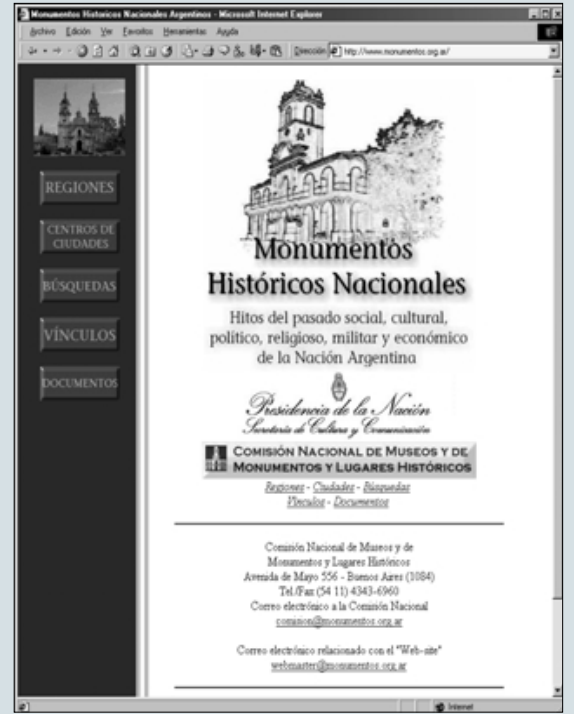

\section{Cursos}

\section{- ICCROM}

http://www.iccrom.org/home.htm

Desde 1960 el International Center for the Study of the Preservation and Restoration of Cultural Property organiza cursos en Roma sobre diversos temas relativos a la protección y la conservación del patrimonio cultural, además también coproduce numerosos cursos internacionales en otros países. En sus páginas web aparece el calendario de estos cursos.

Quizá más interesante sea la base de datos sobre cursos de formación relacionados con el patrimonio cultural organizados en cualquier parte del mundo. Esta base de datos, elaborada junto al Getty Conservation Institute, se actualiza constantemente y contiene información desde 1995. Es la recopilación de cursos sobre este tema más completa existente en Internet. Se puede realizar una búsqueda por tema y país. La entrada a la base de datos está un poco complicada, pues primero hay que seleccionar la opción "Links" del menú principal, después el apartado "Heritage \& Conservation" y finalmente "Training".

- Centro Documentación Arquitectura: Cursos, Congresos, Seminarios, etc (España) http://www.arquired.es/profesion/coaao/cd a/evel.htm

El Centro de Documentación de Arquitectura del Colegio de Arquitectos de Andalucía Occidental ofrece en sus páginas web un apartado donde recopila cursos, congresos, seminarios y masters de arquitectura en general, encontrándose entre ellos aquellos especializados en patrimonio arquitectónico.

Las direcciones que a continuación se presentan recogen información de diversos cursos organizados en España y otros países especializados en patrimonio arquitectónico.

- Máster de Restauración y Rehabilitación del Patrimonio

http://www.masterpatrimonio.edu/

- Máster en Conservación y Restauración del Patrimonio Arquitectónico y Urbano. http://www.upm.es/estudios/propios/catalogo-CONSERV.html

- RICS: Postgraduate Diploma in Building Conservation (Reino Unido)

http://www.cem.ac.uk/dipbuild.htm

- Courses \& education in heritage conservation http://web.rgu.ac.uk/schools/mcrg/stuni.htm

- Town \& Regional Planning Home Page http://www.trp.dundee.ac.uk/

- 1999 NPI Seminars http://www.npi.org/seminars.html

- Built Heritage Conservation http://www.rgu.ac.uk/prospectus/pdbuilt.htm

\section{Investigación}

El mundo de la investigación en patrimonio arquitectónico está escasamente representado en Internet. A nivel internacional pocas son las instituciones de esta naturaleza que se han podido reunir, menos todavía los grupos de investigación. A nivel nacional el panorama es más desalentador, pues no se ha localizado ningún web con información relevante en este apartado. Entre las direcciones seleccionadas es digna de destacar la perteneciente al Masonry Conservation Research Group, pues además de proporcionar información completísima sobre el propio grupo, ofrece una gran cantidad de direcciones web estructuradas en temas con información de interés. 


\section{Centros de Investigación}

\section{- ICCROM}

\section{http://www.iccrom.org/home.htm}

El ICCROM (International Center for the Study of the Preservation and Restoration of Cultural Property) es una organización intergubernamental creada por la Unesco en 1956. Sus actividades son muy diversas y van desde la formación hasta la investigación en temas relacionados con el patrimonio histórico, mueble e inmueble. En el campo de la investigación además de participar en proyecto concretos, tiene como objetivo principal el informar acerca de los logros conseguidos en este campo, para lo cual organiza reuniones donde se discuten problemas y se logran acuerdos internacionales y criterios técnicos estándar. Además lidera informes y estudios como el " Global Survey on Scientific Research for the Conservation of Physical Heritage" que recoge información acerca del estado de la investigación científica en dicha materia. La información reunida en este informe esta almacenada en una base de datos.

\section{- The Getty Conservation Institute (Estados Unidos) \\ http://www.getty.edu/gci/}

El Instituto de Conservación Getty pertenece al J. Paul Getty Trust fundación privada dedicada a las artes visuales, y centra sus actividades en la preservación del patrimonio cultural del mundo: investigación, formación, organización de conferencias y edición de publicaciones. Parte de sus fondos los dedica a la investigación y el resultado de los proyectos que se acometen está disponible en sus páginas web. Para visualizar información sobre los proyectos de investigación hay que elegir la opción "Research WebStracts", donde existe un apartado específico para los proyectos sobre conservación arquitectónica y arqueológica.

\section{- Laboratorios de investigación franceses http://www.culture.fr/culture/conserva- tion/fr/laborato/laborato.htm}

El Ministerio de Cultura francés en su interesante web reúne información de diferente naturaleza. Uno de sus apartados está dedicado a reunir los laboratorios y estudios de investigación relacionados con el patrimonio existentes en Francia. De todos ellos, dos tienen especial interés al estar relacionados con el patrimonio arquitectónico, el Laboratoire de Recherche des Monuments Historiques y el Centre Interrregional de Conservation et de Restauration du Patrimoine. De todos los laboratorios presentados se da una información muy completa.

- Centre for Conservation Studies (Reino Unido) http://www.benvle.dmu.ac.uk/research/con serv/cons.htm

El Centre for Conservation Studies, dependiente de la Escuela de Arquitectura de Leicester, es una asociación de investigadores, profesores y profesionales que trabajan en el campo de la conservación y la gestión del patrimonio cultural. En sus páginas web se ofrece información de sus actividades.

- Is.C.O.M.: Istituto Conservazione Opere Monumentali (Italia)

\section{http://www.iscom.le.cnr.it/Default.htm}

El Istituto Conservazione Opere Monumentali depende del Consiglio Nazionale delle Ricerche italiano. Es un organismo que centra sus actividades en la investigación. En su web se da cuenta de sus todas sus actividades tanto de investigación como formativas. Por el momento tan sólo es consultable en italiano, pero en un futuro muy próximo lo será también en inglés.

\section{Grupos de investigación}

- Masonry Conservation Research Group (Reino Unido)

http://web.rgu.ac.uk/schools/mcrg/mcrghome.htm

Este web pertenece al grupo de investigación sobre la conservación de la mampostería. Sus componentes pertenecen a la Universidad Robert Gordon de Aberdeen, Escocia, y son especialistas en muy diversas disciplinas: construcción, arquitectura, geología, química, etc. Contiene una información muy completa acerca del grupo y sus actividades. En su apartado "People" aparecen todos sus miembros con su especialidad y correo electrónico; en "Research Areas" aparecen los resúmenes de todas las investigaciones llevadas a cabo y las que se están realizando en la actualidad, en muchos casos además de la información básica se añade una información más completa con enlaces a otros apartados y documentos. El web se completa con una relación de las publicaciones de los miembros del grupo y con una recopilación bastante extensa e interesante de direcciones Internet de páginas de interés con informaciones diversas sobre el patrimonio arquitectónico.

\section{Publicaciones}

Internet ofrece un gran abanico de posibilidades para el mundo de las publicaciones. En Internet se puede: poner simplemente una página informativa sobre una publicación en papel para dar mera cuenta de la existencia de la misma, añadir los sumarios y finalmente ofrecer el texto íntegro de la misma.

La naturaleza de las publicaciones puede ser también muy diverso, se puede encontrar desde una revista periódica de aparición regular hasta un texto concreto pasando por un diccionario temático.

A continuación se presentan publicaciones en sus diferentes tipos y modalidades con información de interés acerca del patrimonio arquitectónico. Como puede apreciarse a nivel internacional existen muy pocas que estén especializadas en este tema, menos aún en el ámbito nacional.

En este apartado también se han incluido librerías electrónicas especializadas en arquitectura, ya que la compra de libros a través de Internet es un servicio en alza.

\section{Revistas especializadas}

\section{- Publicaciones del IAPH}

\section{http://www.iaph.juntaandalucia.es/form_ibo} I.html

Uno de los objetivos del Instituto Andaluz del Patrimonio Histórico es el de generar una serie de publicaciones complementarias entre si, dirigidas a la formación y actualización profesional especializada de los colectivos comprometidos con la conservación, documentación, gestión y difusión del patrimonio, con especial atención a quienes desarrollan su actividad dentro del ámbito andaluz. En el web del IAPH se da entrada tanto al catálogo de publicaciones del propio instituto como a las diferentes revistas editadas periódicamente por el 
mismo. En el caso de las publicaciones periódicas se adjunta un índice del contenido de cada uno de los números, salvo en los dossieres temáticos que acompañan a la publicación "PH. Boletín del Instituto Andaluz del Patrimonio Histórico" presentados a texto completo.

\section{- Ars Sacra (España)}

\section{http://www.arssacra.com/}

Ars Sacra es una revista trimestral publicada por el Secretariado Nacional de la Conferencia Episcopal Española. Está especializada en todo lo relativo al arte sacro actual y a la restuaración de los templos. Este webs contiene información muy completa sobre la revista: redacción y colaboraciones, sumarios de los números publicados, suscripciones, envíos de artículos, etc.

\section{- CoRé (Francia)}

http://www.culture.fr/culture/editions/core.htm Revista semestral editada por la SFIIC (Section Française de I'Institut International de Conservation) asociación sin ánimo de lucro que agrupa a especialistas en la conservación del patrimonio cultural. En las páginas web de esta asociación aparece el sumario del último número de la revista.

\section{Revistas Electrónicas}

- Conservation Newsletter (Estados Unidos) http://www.getty.edu/gci/newslettere.html Es una revista electrónica, publicada tres veces al año por el Getty Conservation Institute en inglés y español, que comenzó a editarse a partir de 1991. Todos los artículos que han aparecido en la misma se encuentran a texto completo en el web.

\section{- Traditional Building Magazine (Estados Unidos) http://www.traditionalbuilding.com/index. html\#MENU}

Traditional Building Magazine es una publicación periódica impresa americana dirigida a los propietarios de edificios antiguos y a los profesionales que trabajan en el mantenimiento de los mismos, editada por un grupo de empresarios del sector. Este mismo grupo de empresarios es el responsable de las páginas web, donde además de dar información de sus productos y servicios, se presentan a texto completo alguno de los artículos aparecidos en la revista.
Textos

- Documents on cultural heritage protection http://web.rgu.ac.uk/schools/mcrg/stdoc.htm EI ICCROM (International Center for the Study of the Preservation and Restoration of Cultural Property) en su sección de enlaces presenta un apartado denominado "Documents on Cultural Heritage Protecction", donde reúne una gran cantidad de direcciones de páginas, sobre todo procedentes de lo webs de la Unesco y de Icomos, donde se pueden consultar a texto completo los documentos de carácter internacional más importantes.

\section{Diccionarios}

\section{- Conservation Glossary http://www.trp.dundee.ac.uk/research/glos sary/glossary.html}

Lo que presentan estas páginas web es un glosario de términos relacionados con la conservación del medio construido. El responsable del trabajo es Neil Grieve, miembro del Centre for Conservation and Urban Studies de la Universidad de Dundee en el Reino Unido. El glosario puede ser consultado de dos formas diferentes: o bien entrando por un índice alfabético o bien tecleando sobre el formulario adecuado el término deseado. La respuesta obtenida es una definición del término solicitado, en algunos casos el texto es acompañado de una imagen. Este diccionario también se beneficia de las posibilidades de crear vínculos entre páginas web, pues cada vez que sale en la definición del término solicitado otro término definido en el glosario, existe la posibilidad de ir directamente al mismo.

\section{Librerias y editoriales}

\section{- The ArchitectStore}

\section{http://architectstore.com/books/}

Desde esta página se da entrada a dos librerías electrónicas: Amazon.com, servicio pionero en la compra de libros a través de Internet, y Powell's Books, otro de los grandes del sector. Estos dos servicios electrónicos de compra de libros nos permiten buscar en sus catálogos y hacer peticiones vía ordenador.

- Interlibro. Libros de arquitectura http://www.interlibro.com/
Interlibro es un servicio de importación, exportación y distribución de libros especializados en arquitectura, que mantiene relación con las principales editoriales de Arquitectura del mundo, lo que nos permite ofrecer al público los títulos mas especializados.

\section{Listas de Distribución}

Una lista de distribución se puede definir como un conjunto de personas que se comunican a través de correo electrónico, con la peculiaridad de que, además de poder mandarse mensajes individualizados entre ellas, tienen la posibilidad de enviarlos simultáneamente a la totalidad de los componentes de la misma. Las listas de distribución son un buen instrumento de relación para los interesados en un mismo tema, ya que les permite intercambiar noticias y experiencias, formular preguntas y asistir a debates, participando directamente en ellos o siendo, sí así lo desean, meros espectadores.

Las listas de distribución están disponibles en grandes ordenadores y son gestionadas por programas informáticos concebidos para tal fin. El gestor de listas más difundido en estos momentos es el denominado Listserv. Se pueden también citar Listproc, Majordomo y Mailbase como otros gestores de listas de bastante difusión.

Un gestor de listas es capaz de administrar varias listas simultáneamente. Cada una de ellas se identifica con un nombre propio y la dirección de la máquina donde se encuentra ubicada, es decir: lista@máquina (ej.: grumetes@listserv.rediris.es).

Todos los programas gestores de listas realizan básicamente las mismas funciones, pero se diferencian unos de otros en los entornos informáticos para los que han sido diseñados y en los comandos que utilizan para realizar dichas funciones. Las funciones básicas de un gestor son las siguientes: suministrar información sobre la lista y sus componentes, permitir la suscripción y la anulación de una suscripción, hacer búsquedas en la base de datos que acumula todos los mensajes enviados para sus distribución y recuperarlos posteriormente. 
Para más información acerca del uso de las listas de distribución consultar la siguiente dirección: http//www.rediris.es/list/

A continuación se citan las listas de distribución que por su temática están directamente relacionados con el patrimonio arquitectónico.

- Preservatión-L

Tema: conservación y preservación de patrimonio arquitectural.

Idioma: inglés.

Suscripción: enviar el mensaje 'subscribe preservation-l" a listserv@netcom.com

- Conservation-research

Tema: conservación de objetos de arte y de edificios.

Idioma: inglés.

Más información:

http://www.mailbase.ac.uk/lists/conservation-research

- Conservation Distlist

Tema: conservación de materiales culturales. Idioma: inglés.

Suscripción: enviar el mensaje "subscribe

Distlist su nombre" a

consdist-request@lindy.stanford.edu

\section{- ICCOM-CC}

Tema: es una lista de distribución mantenida por "International Conservation Committee Council of Museums" (ICOM). Esta lista está abierta al público en general, pero sólo pueden mandar mensajes los miembros de la institución.

Idioma: inglés.

Suscripción: enviar el mensaje "subscribe ICCOM-CC nombre y apellido" a listserv@home.ease.lsoft.com

\section{- Engineering-masonry}

Tema: mampostería y su uso en ingeniería y construcción.

Idioma: inglés

Más información:

http://mailbase.ac.uk/lists/engineeringmasonry

- WAM-L

Tema: arquitectura en general.

Idioma: español e inglés.

Suscripción: enviar el mensaje "subscribe wam_l" a wam_I_mgr@izones.com.

- Arquitectura-I

Tema: arquitectura en general. Idioma: español.
Suscripción: enviar el mensaje "suscribe arquitectura-I nombre y apellido" a listserv@conicit.ve

Teresa Abejón Peña, Elena Fernández Sánchez Ángeles Maldonado Martínez

Centro de Información y Documentación Científica (CINDOC) (CSIC)

\section{Bibliografía}

Fernández Sánchez, Elena [et al.]. Urbanismo, Arquitectura y Construcción en Internet. Madrid: CINDOC, 1998. 201 p.

Fontes Blanco-Loizelier, Fernando L. Guía española de recursos en Internet sobre Prehistoria, Arqueología, Historia Antigua y Gestión del Patrimonio. Complutum, $n^{\circ}$ 8, 1997, pp. 374-385.

Ortega Vaquero, Isabel. "Webs de arquitectura: una aproximación y valoración de los recursos de información electrónicos nacionales". PH. Boletín del IAPH, n²2, 1998, pp. 123134

\section{Paseos virtuales por Jaén: el patrimonio cultural de Úbeda y Baeza en Internet}

El acceso multimedia a nuestra rica herencia cultural resulta cada vez más asequible y ofrece la posibilidad de conocer e incluso realizar una visita virtual a los monumentos y otros bienes históricos y naturales de las distintas provincias andaluzas.

En este caso, se ofrece una muestra de los distintos itinerarios culturales a través de Internet que se pueden realizar por Jaén, fundamentalmente por Úbeda y Baeza, unas de sus poblaciones con mayor riqueza patrimonial. Los destacados valores urbanísticos y arquitectónicos de estas ciudades, heredados de su época de esplendor en el siglo XVI, las convierte en candidatas a integrar la Lista de Sitios Patrimonio de la Humanidad de la UNESCO.
Iniciamos el recorrido con la página Web de Altavista "La base de datos de Andalucía" (http://www.bd-andalucia.es/), que a través del mapa de esta región ofrece acceso a diversos aspectos generales de las ocho provincias andaluzas, como el clima o el número de habitantes, y a una lista de municipios sobre los que se puede encontrar información más detallada relacionada con su historia, su cultura y sus monumentos, el ocio, las fiestas así como el transporte y otros servicios.

Concretamente destacamos el ejemplo de Úbeda. Después de consultar la breve reseña histórica a la que se accede a través del botón "Historia", se recomienda picar en el icono "Cultura", que nos conducirá a un paseo virtual por los monumentos más destacados de la ciudad, con breves descripciones de cada uno de ellos y fotografías de los más destacados.

El siguiente itinerario que destacamos por su calidad, aunque los textos están redactados en inglés, ha sido diseñado por la Universidad de Granada (http://kal-el.ugr/ubeda.html). El sitio web se inicia con una descripción concisa de los principales monumentos de Úbeda y Baeza y de la singularidad del desarrollo artístico del Renacimiento en las dos localidades.

A continuación, puede realizarse un ameno recorrido por el patrimonio arquitectónico de esta ciudad, acompañado de bellas imágenes y de reseñas, en algunos casos bastante exhaus- 